\title{
Acute oesophageal necrosis syndrome
}

\author{
George Garas, Constance Wou, Joseph Sawyer, lakovos Amygdalos, Stuart Gould \\ Department of General Surgery, Northwick Park Hospital, North West London Hospitals NHS Trust, Harrow, Middlesex, London, UK \\ Correspondence to George Garas, garas_george@yahoo.com
}

\begin{abstract}
Summary
An 89-year-old woman with a known hiatus hernia presented to the accident and emergency department with acute onset epigastric pain. CT of the thorax and abdomen revealed a large hiatus hernia with mesentero-axial volvulus but no evidence of strangulation. A large aneurysmal aortic arch and descending aorta were visible with associated mural thrombus. As the pain was worsening, following discussion with the patient, the decision to operate was taken. The hiatus hernia was successfully reduced and the stomach looked healthy. The oesophagus, however, appeared black almost throughout its entire length consistent with acute oesophageal necrosis syndrome, a rare and lethal disease. Left lateral thoracotomy followed by cervicotomy was performed to retrieve a healthy oesophageal segment, which was anastomosed to the cardiac end of the stomach. Despite treatment in the intensive care unit, the patient's condition progressively deteriorated and she died of multiorgan failure 12 days later.
\end{abstract}

\section{BACKGROUND}

This case describes a very rare syndrome, acute oesophageal necrosis (AON), which is associated with a high mortality (38\%). ${ }^{1}$ The presentation of our case is atypical in many ways.

First, the patient was female and the only presenting feature was epigastric pain with no evidence of upper gastrointestinal haemorrhage (commonest presenting feature of $\mathrm{AON})^{2}$ or lactic acidosis to suggest visceral ischaemia. This illustrates the individuality of our case as AON predominantly affects males (male:female ratio is $4: 1$ ) and in $>70 \%$ of cases the presenting feature is haematemesis and melaena. ${ }^{1}$

In addition, the patient's age was atypical with only two (of 112) other cases of AON been reported in the literature in patients of the same or more advanced age (89 and 91, respectively). 34

CT of the thorax and abdomen failed to demonstrate oesophageal pathology and the diagnosis was made intraoperatively and confirmed histopathologically.

Finally, this case illustrates that AON, despite its rarity, should be considered in patients presenting with epigastric pain, particularly in the presence of predisposing factors such as arterial disease (aneurysmal aortic arch and descending aorta with an associated mural thrombus) and disruption of physiological antireflux mechanisms (large hiatus hernia). ${ }^{15}$ As the disease can develop rapidly, ${ }^{6}$ early suspicion can promote timely diagnosis and prompt initiation of treatment, which has been shown to improve patient outcome. ${ }^{2}$

\section{CASE PRESENTATION}

An 89-year-old woman presented to the accident and emergency department with acute onset, cramping epigastric pain that had developed over a few hours. She had never experienced similar symptoms before. Her medical history was remarkable only for hiatus hernia and hypothyroidism and the only medication she was on was levothyroxine 100 mcg tablets once a day. There was no relevant family history of note. She was a non-smoker, non-drinker and lived alone. She was mobilising outdoors with a stick, being able to independently care for herself. Review of systems was unremarkable and the patient had opened her bowels normally earlier that day.

On examination, the patient was uncomfortable and belching. She had a mildly distended abdomen with marked tenderness over the epigastrium but no peritonism. She was haemodynamically stable. Cardiovascular, respiratory and central nervous system examinations were unremarkable as was the electrocardiogram (ECG), urine dipstic and arterial blood gas analysis on admission. She was put 'nil by mouth' and given analgesia in addition to been started on proton-pump inhibitors and antiemetics.

However, the next day the pain worsened and hence the patient underwent CT of the thorax and abdomen to identify the underlying cause.

\section{INVESTIGATIONS}

CT of the thorax and abdomen revealed a large hiatus hernia with mesentero-axial volvulus but no evidence of strangulation. A large aneurysmal aortic arch and descending aorta were visible with associated mural thrombus (figure 1). There was no intra-abdominal pathology except of the presence of uncomplicated sigmoid diverticulosis.

Histology of the oesophagus resected during surgery showed features of ischaemia and associated haemorrhagic necrosis. There was no evidence of dysplasia or malignancy.

\section{DIFFERENTIAL DIAGNOSIS}

The differential diagnosis included a strangulated hiatus hernia.

\section{TREATMENT}

As the pain was not resolving, following discussion with the patient, the decision to proceed with surgery was 


\section{BMJ Case Reports}

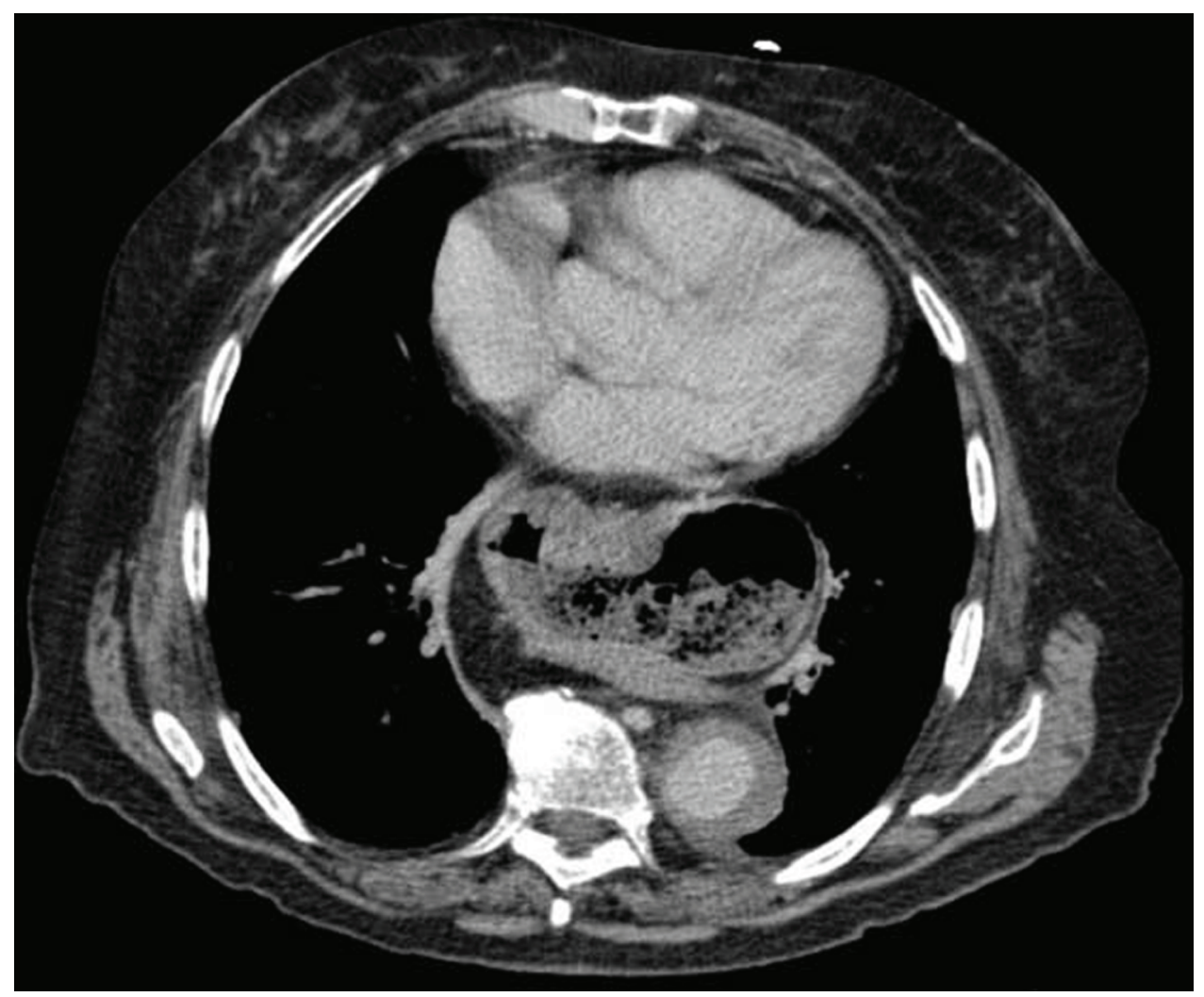

Figure 1 Large hiatus hernia with associated mesentero-axial volvulus. An aneurysmal descending aorta is also visible with an associated mural thrombus.

taken. An upper midline laparotomy incision was performed and the hiatus hernia successfully reduced transhiatally. However, as the distal oesophagus was reduced into the abdominal cavity it was seen to be black, thinned and extremely friable suggesting ischaemic necrosis. It spontaneously dissected. A decision to perform a left lateral thoracotomy was taken to try and find a viable oesophageal segment. However, the intrathoracic oesophagus was also necrotic throughout its length necessitating a cervicotomy to trace it from its origin. A healthy segment of the cervical oesophagus was identified and this was anastomosed to the cardiac end of the stomach, which was brought in the neck through a gastric pull-up.

The decision to perform such invasive surgery was taken as the patient had explicitly stated during consenting that she wanted the continuity of her alimentary tract to be preserved to sustain her quality of life even if this would potentially reduce her chances of survival. In addition, throughout the operation the anaesthetist had no particular concerns about the patient's status and at all times was happy for the operation to continue. Four units of packed red cells were transfused intraoperatively.

Following the operation, the patient was transferred to the intensive care unit, where she was started on empirical intravenous antibiotics and total parental nutrition.

\section{OUTCOME AND FOLLOW-UP}

Despite aggressive surgery and treatment in the intensive care unit, renal function began to deteriorate and multiorgan failure rapidly ensued with worsening metabolic acidosis and hyperkalaemia. The patient died 12 days following hospital admission.

\section{DISCUSSION}

$\mathrm{AON}$ is a very rare clinical entity with only 112 cases ever been described. ${ }^{2}$ As on endoscopy, the oesophageal mucosa appears circumferentially black and the underlying pathophysiology involves ischaemic death of the oesophagus; $\mathrm{AON}$ is also known as 'black oesophagus', 'acute necrotising oesophagitis' or 'oesophageal stroke'. ${ }^{2}$ The disease was first described by Goldenberg et al in 1990 and classified as a distinct syndrome by Gurvits et al in 2007. ${ }^{16}$

The commonest presentation of $\mathrm{AON}$ is with features of upper gastrointestinal haemorrhage. ${ }^{2}$ Haematemesis and melaena are present in $>70 \%$ of cases. $^{5}$

AON predominantly affects males with a male:female ratio of $4: 1$. The mean age of presentation is 68.44 years although it has been described to occur over a very broad age range (19-91 years). AON is associated with certain conditions. These include gastric outlet obstruction or volvulus, shock, irradiation, trauma and Stevens-Johnson syndrome. $^{2}$

The differential diagnosis of AON ('black oesophagus') includes melanosis and pseudomelanosis, malignant melanoma, acanthosis nigricans, dye ingestion and caustic injury. ${ }^{2}$

The exact mechanism underlying $\mathrm{AON}$ is not well understood, but it is thought that its aetiopathogenesis is multifactorial. This consists of tissue hypoperfusion, downregulated local protective mechanisms and an influx of gastric contents on the already compromised oesophageal mucosa. ${ }^{5}$ Our patient exhibited all these features due to her large hiatus hernia and extensive aneurysmal aortic disease (affecting both the arch and descending aorta) with associated mural thrombus. Due to the better vascularised proximal 


\section{Learning points}

- Clinical features of AON are predominantly associated with upper gastrointestinal haemorrhage and can therefore mimic more common pathologies. ${ }^{2}$

- AON has a high mortality and should be considered in patients presenting with symptoms of upper gastrointestinal haemorrhage.

- AON can develop rapidly thus prompt recognition is vital to ensure no delay in initiation of treatment. ${ }^{2}$

- Early treatment of AON has been shown to improve patient outcome. ${ }^{2}$

- If surgery for AON is performed, restoration of oesophagogastric continuity should be delayed. ${ }^{1}$

and middle parts of the oesophagus compared to the distal segment, it is not surprising that $\mathrm{AON}$ starts distally (more 'watershed' blood supply and thus more prone to ischaemia) and extends proximally as the disease progresses. ${ }^{5}$

There is also a possible link between AON and certain pathogens, such as cytomegalovirus, ${ }^{78}$ Candida albicans 910 and Klebsiella pneumoniae. ${ }^{11}$

It is thought that the number of cases of $\mathrm{AON}$ is greatly underestimated. This may be partly due to its potential for subclinical presentation. ${ }^{5}$ Given its high mortality, it is important that surgeons and physicians recognise presenting features of $\mathrm{AON}$ so that lifesaving treatment can be instigated promptly. Clinical features of $\mathrm{AON}$ are predominantly associated with upper gastrointestinal haemorrhage and can therefore mimic more common pathologies. ${ }^{2}$

Opinions about the treatment of AON vary among authors but treatment generally involves an initial conservative approach to optimise the patient. This includes keeping the patient 'nil by mouth' and administering parenteral proton-pump-inhibitors and nutrition. In certain cases of AON, infective causes are implicated and in such cases antimicrobial therapy is recommended. ${ }^{5}$

Surgical treatment involves prompt oesophagectomy and drainage of any mediastinal collection or abscess, which can result from perforation of the oesophagus. Restoration of oesophagogastric continuity should be delayed. ${ }^{1}$

Prognosis of $\mathrm{AON}$ is poor with one in three patients dying (38\%). ${ }^{1}$ In those patients that survive, AON can lead to chronic problems such as oesophageal stenosis or strictures seen in $>10 \%$ of patients. ${ }^{5}$

\section{Competing interests None}

Patient consent Obtained.

\section{REFERENCES}

1. Gurvits GE, Shapsis A, Lau N, et al. Acute esophageal necrosis: a rare syndrome. J Gastroenterol 2007;42:29-38.

2. Day A, Sayegh M. Acute oesophageal necrosis: a case report and review of the literature. Int J Surg 2010;8:6-14.

3. Augusto F, Fernandes V, Cremers Ml, et al. Acute necrotizing esophagitis: a large retrospective case series. Endoscopy 2004;36:411-15.

4. Ben Soussan E, Savoye G, Hochain P, et al. Acute esophageal necrosis: a 1-year prospective study. Gastrointest Endosc 2002;56:213-17.

5. Gurvits GE. Black esophagus: acute esophageal necrosis syndrome. World J Gastroenterol 2010:16:3219-25.

6. Goldenberg SP, Wain SL, Marignani P. Acute necrotizing esophagitis. Gastroenterology 1990;98:493-6.

7. Barjas E, Pires S, Lopes J, et al. Cytomegalovirus acute necrotizing esophagitis. Endoscopy 2001;33:735.

8. Trappe R, Pohl H, Forberger A, et al. Acute esophageal necrosis (black esophagus) in the renal transplant recipient: manifestation of primary cytomegalovirus infection. Transpl Infect Dis 2007:9:42-5.

9. Grudell AB, Mueller PS, Viggiano TR. Black esophagus: report of six cases and review of the literature, 1963-2003. Dis Esophagus 2006;19:105-10.

10. Kim YH, Choi SY. Black esophagus with concomitant candidiasis developed after diabetic ketoacidosis. World J Gastroenterol 2007;13:5662-3.

11. Liu YH, Lin YS, Chen HJ, et al. Klebsiella pneumoniae deep neck infection with acute necrotizing esophagitis. South Med J 2009;102:219.

This pdf has been created automatically from the final edited text and images.

Copyright 2011 BMJ Publishing Group. All rights reserved. For permission to reuse any of this content visit http://group.bmj.com/group/rights-licensing/permissions.

BMJ Case Report Fellows may re-use this article for personal use and teaching without any further permission.

Please cite this article as follows (you will need to access the article online to obtain the date of publication).

Garas G, Wou C, Sawyer J, Amygdalos I, Gould S. Acute oesophageal necrosis syndrome. BMJ Case Reports 2011;10.1136/bcr.10.2010.3423, date of publication

Become a Fellow of BMJ Case Reports today and you can:

- Submit as many cases as you like

- Enjoy fast sympathetic peer review and rapid publication of accepted articles

- Access all the published articles

- Re-use any of the published material for personal use and teaching without further permission

For information on Institutional Fellowships contact consortiasales@bmjgroup.com

Visit casereports.bmj.com for more articles like this and to become a Fellow 